\title{
Training Mode of Logistics Talents Based on Internet Era in Application Colleges and Universities
}

\author{
Shufan Zhu ${ }^{1, a^{*}}$ Rongyan Zhu ${ }^{2, b}$ and Xiaofen Zhou ${ }^{3, c}$ \\ ${ }^{1}$ Lecturer, Senior Logistics Division, School of Logistics Management, Wuhan Technology \\ and Business University, No.3, Huangjiahu west road, Wuhan, Hubei, China \\ ${ }^{2}$ Ph.D, Hubei Business Service Development Research Center, Wuhan Technology and \\ Business University, No.3, Huangjiahu west road, Wuhan, Hubei, China \\ ${ }^{3}$ Lecturer, Senior Logistics Division, School of Logistics Management, Wuhan Technology \\ and Business University, No.3, Huangjiahu west road, Wuhan, Hubei, China \\ azhu_shufan1@163.com, 'Zhurongyan1985@163.com,,103343280@qq.com
}

Keywords: Applied universities; Internet age; Logistics talent training mode; Ecosystem model

\begin{abstract}
With Internet platform and information communication technology having poured into traditional logistics industry, it is becoming more and more important to train logistics management talents to adapt to transformation and upgrading of logistics enterprises. This paper presents Training mode of logistics talents in applied universities in the Internet era. This paper elaborates existing problems and concept of logistics personnel training mode in applied colleges and universities under the Internet age, analyzing applied objective, content, and security of logistics personnel training mode in colleges and universities. Cultivating talents' mastering new technology to increase their service ability for social and economic transformation and upgrading, also has become inevitable trend and key tasks of applied colleges and universities in China.
\end{abstract}

\section{Introduction}

As intelligent transportation, intelligent storage, energy conservation and environmental protection technology, especially the Internet of things, big data, cloud computing and other information technology is widely used in the field of logistics, Internet-logistics are constantly changing many aspects of traditional logistics operation mode and efficiency level from technology, equipment, business model and so on, making logistics more wisdom and intelligent. Internet model integrates into traditional logistics business model, with the corresponding that logistics demand pattern also have changed greatly. How to combine discipline characteristic, enhance social applicable degree of talent training, enhance capacity of social services become the mainstream development ideas and development mode of higher education in the new period. Meanwhile, how to correctly understand and grasp real-time demand of logistics industry, to explore applied talents training mode of sustainable development, has become top priority.

\section{Research Status}

Research on the Cultivation of Internet-logistics Talents. In recent years, scholars have studied from different angles of talent training mode in Internet environment. Q. Sheng utilized intelligent management system in logistics management teaching practice bade to realize intelligent and scientific management of teaching and practical training[1]. Q. Xu put forward technical skill demand and restriction factor analysis of logistics information talent training in the background of Internet[2]. S.L. Wang proposed several mature modes of Internet-education, including public education resources, learning based ability, MOOCS and so on[3]. Y. Wang analyzed new situation of logistics industry development trend and talent ability demand, putting forward three thinking and ten logistics skills type that logistics personnel should possess in the Internet era, such as open mind, embrace thinking and crossover thinking[4]. What's more, these logistics talents should be proficient in project management, accounting management, data mining and data analysis, financial 
management, supply chain management, being good at communication and sharing, etc. L. Cai et al. raised "three phase ability and whole process of literacy" personnel training mode, "two platform and two module" curriculum system and "Study-training-competition" teaching pattern, on account of logistics management personnel training adapting to transformation and upgrading of logistics enterprises[5][6].

Literature Review. These studies have some guiding significance for logistics talents cultivation of applied universities in the Internet environment, which provides research foundation for the paper. However, in general, there are obvious deficiencies.

Talents training mode only focus on one aspect in applied colleges and universities, relatively single, lacking systemic framework of logistics personnel training system, which not overall consider systemic training mode.

Although different ways of cultivating talents have been proposed, not focusing on students, cultivation key consider training programs or schools are the main subjects.

Existing pattern excessively emphasis on talent skills needed by logistics enterprise for applied logistics personnel training in colleges and universities, ignoring Internet influence on logistics enterprises. Nevertheless, training of students' knowledge and skills transfer is the demand of logistics industry for talents.

\section{Background of Logistics Talents Training Mode of Applied Universities Based on the Internet Era}

Current Situation Analysis of China's Logistics Industry. With the rapid development of Internet since the 21 st century, logistics industry has grown rapidly and logistics service level has improved significantly in china. Traditional logistics enterprises services personalized clients with standardized products and standardization realize specification. With standardization changing logistics, simple logistics business platform transfer to logistics specification. Individuals can more reflect service value of logistics enterprises, realizing integration, diversification, personalization and customization of logistics business. What's more, personalization infiltrates into all logistics links, promoting transformation and upgrading of logistics enterprise, and different forms of logistics enterprises will lead all roads to Rome. In responding of different elements integration, such as express delivery, distribution, warehousing, trunk, multimodal transport, international pay, electric business, IT technology becomes the most important soft power in logistics enterprise. Therefore, the fourth logistics gradually appear with resource integration, virtual logistics, scheme design. Under this background, logistics industry demand for logistics talent have had great changes, with applied logistics talents are going to become the logistics industry reserve talents who possess Internet thought, industry forward-looking, strong adaptable ability to Internet model.

Existing Problems of Logistics Talents Training Mode for Applied Universities Based on the Internet era. In regard of urgent need of professional skills talents for Internet-logistics, there are still some problems in applied logistics talents cultivation, such as unclear applied talents cultivation orientation, curriculum system do not matching with career demand cultivation which is a bit single, students' autonomous learning resources scarcity. In consequence, skills training is the process of experience accumulation, which must be completed in long practical operation. At present, talent training strengthen practical teaching parts, conserving three modules of course modes including scientific knowledge-technology capability-comprehensive quality, in that technical capabilities include logistics analysis and development ability, logistics post ability and logistics circulation knowledge ability, however, this way is that main teaching curriculums are pushed to students by teachers, and students lack of independent right to choose classes, passive acceptance. At the same time, there are rare double-professionally-titled teachers of Internet-logistics professional structure. Although cooperating with different types of logistics enterprise, university-enterprise cooperation is limited to different period of training and internships, deep cooperation mechanism having not yet been established and limited lasting university-enterprise joint training. 
Demand Analysis of Talents Training in Logistics Industry. At present, social economy has entered a new stage of innovation driving development of the new structure in our country. With urgent need of innovative logistics talents by the Belt and Road development strategy and internet, it is important for high universities to foster high skills, high-quality practical, and innovative talents, who have innovation spirit of open, embracing and cross-border thinking.

From the perspective of logistics enterprise, Internet plus mean promotions and specification of information construction in logistics enterprises, that means that Internet plus present different enterprises and industry to develop Internet plus actions, then, logistics enterprises need to provide personalized, customized, integrated high-quality service for other enterprises in the Internet plus environment. How to realize Internet-plus, we can initiate from internal and external perspective of enterprises. In the first, how to optimize business process of logistics enterprises to realize Internet-plus, then, how to effectively connect with enterprise or industry after realizing Internetplus. Therefore, requirements analysis of applied logistics personnel training in colleges and universities must realize two aspects of actual demand based on logistics enterprises implement internet-plus, leading to reflecting core elements and constant improvement of logistics personnel training

First of all, the first demand of logistics enterprises realizing Internet-plus are technical skills requirements needed by internal logistics enterprise business process optimization, including: information technology utilization of information technology practice layer, early warning and emergency response and business process optimization and improvement. On the other hand, data collection and data mining, design and operation of logistics information system, logistics information demand management involved in information technology and existing business process integration.

Secondly, in view of the second requirement of logistics enterprises to realize Internet-plus, technical skills requirements derived from logistics enterprises and service enterprises, including needs analysis and interface processing of different enterprise business and docking system, cost accounting, logistics information technology optimization, logistics business information tracking and analysis.

Consequently, applied logistics personnel training in colleges and universities, mainly include Internet-plus logistics operation and promotion and Internet-plus logistics information system planning and construction, Internet-plus logistics business process optimization and restructuring, Internet-plus logistics information data acquisition and mining, Internet-plus logistics information system solutions design, Internet-plus logistics information technology application.

\section{Reform and Decision-making of Logistics Personnel Training Mode in Applied Universities Under the Internet Era}

Definition of Logistics Personnel Training Mode in Applied Universities Based on the Internet Era. Internet-plus applied logistics personnel training mode innovate traditional management pattern in logistics enterprise based on the background of the Internet era. This mode consider "open, sharing, win-win" as idea, and consider supply chain which mean network, win-win and cooperation as a platform to establish an effective applied logistics personnel training mode. The core idea of logistics talent training mode in the internet background: to cultivate ability to analyze and solve practical problems in the logistics fields, especially in the field of Internet e-commerce logistics. Meanwhile, This mode can take into account improving practical work ability of logistics talents, for example, abilities of Internet logistics system planning, Internet information system planning and construction, Internet e-commerce logistics operation.

Objectives. Based on current logistics industry talent demand, talents cultivation mode should follow overall requirement of logistics disciplines, strengthening practice teaching and innovation teaching mode around the Internet thinking to cultivate applied and adaptive logistics professionals, embodying in the following aspects:

Promote education teaching reform of logistics talents in applied university. This thesis focuses on requirements specification of enterprise logistics talents to reform teaching method and improves 
talents cultivation scheme design, curriculum reform, practice training and teaching evaluation in the internet era.

Promote innovation of logistics personnel training mode under the Internet environment. This mode implement curriculum innovation from series of contents, for example, optimizing allocation of education resources, promoting education fairness, respecting students' individual differences, meeting individual needs of students, breaking through constraints of learning time and space, speeding up study way change and enriching curriculum innovation contents.

Promote cultivation of students' professional quality. Simulating real situation of enterprises and relying on enterprise project, this mode cultivate students' thinking mode of open crossover through joint cultivation of theoretical classroom, experimental training and internship.

\section{Contents}

Combine Development Needs of Internet and Logistics Industry and Adjust Direction of Personnel Training. Logistics industry is not an independent domain, depending on other enterprise requirements. personnel training should not only meet demand for logistics talent of traditional industry, but also meet new demand for logistics industry resource integration of emerging industry. Based on development plan of logistics talent training mode in applied universities, it should be more comprehensive, interdisciplinary, timeliness and innovative thinking in talent cultivation. With modern logistics industry changing day by day, training of logistics personnel also need to keep pace with Times, not only requiring students to master professional knowledge and skills in the field, but also needing students with solid cultural quality and humanistic accomplishment to reflect students' comprehensive ability.

Therefore, logistics professional should transport high quality applied talents who are open mind to keep up with market under the age of Internet. Meanwhile, it should be relying on talent ability demand research of Internet-plus logistics in order to improve logistics personnel training quality, researching on training mode, teaching content, teaching mode, teaching quality, then, building logistics personnel training system based on project, customization, platform and ecology in the Internet era. The "four-integrated" Internet-plus logistics talent training ecosystem model is shown in Fig. 1.

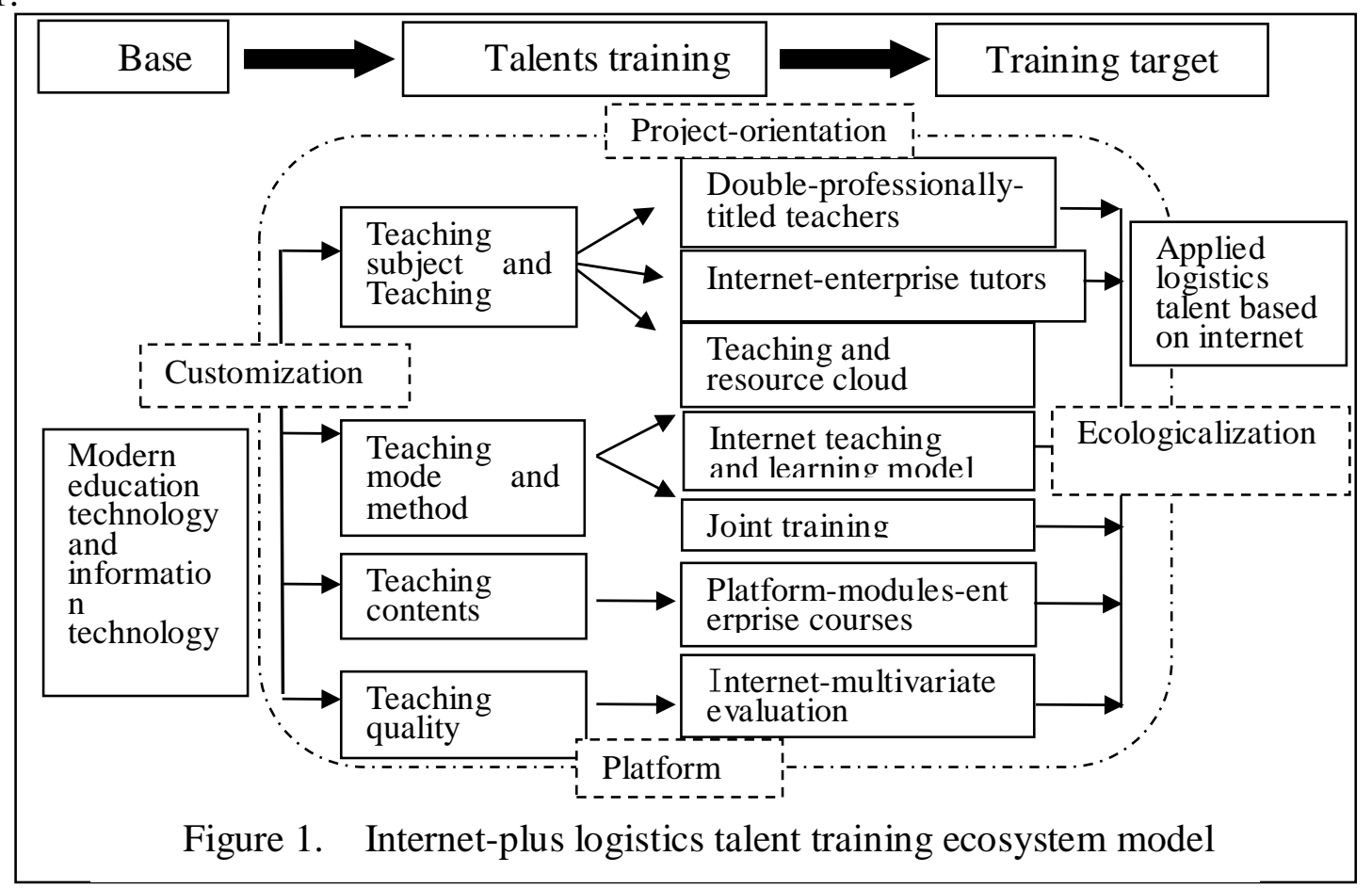

Relying on enterprise project, this mode adopts customized training mode and realize applied talents cultivating ecological system with the help of education technology and information technology platform, reducing resource waste in the process of personnel training and improving efficiency and effectiveness of talent training. In general, Main body of teaching and teaching resources mainly are double-professionally-titled teachers and enterprise mentors, taking joint 
training teaching mode with teaching and resources cloud platform, then we can collaborate enterprise mentors together to adjust talent training scheme. Meanwhile, teaching contents are "platform-module-enterprise curriculums" specialized course system, relying on teaching resource platform and enterprise platform to divide course system into different series modules. Finally, we can evaluate teaching quality by traditional evaluation and Internet-plus multiple evaluation, realizing whole process evaluation and comprehensive evaluation, and emphasizing evaluation of students' learning process.

Relying on Needs of Logistics Talents in the Internet Era, Perfecting Construction of Specialized Courses and Establishing Courses Structure Systems based on Matrix "Platform-Modules-Enterprise Courses". We should cooperate with logistics companies to build scientific curriculum systems for professional jobs. To give full play to the role of multi-party resources, we will extend logistics talent curriculum platform to social platform. Meanwhile, according to the laws of skilled personnel training as well as job qualifications for high skilled talents related with professional post(group) in logistics enterprises ,we can analyze typical tasks assignment and induct post professional ability, embracing three main lines of professional ability, innovation ability and quality education.

The so-called matrix organization form is designed from horizontal and vertical dimensions. On the horizontal dimension, curriculum systems are divided into several modules, such as theoretical teaching series, practical teaching series and research and innovation training series. From the vertical dimension, course systems are divided into four courses: general education class module, Professional disciplines education course module, specialized main course module, professional elective course module. Practical teaching series can be divided into curriculum experiment and curriculum design, course practice, cognition practice and production practice, graduation practice and graduation thesis (design). Theoretical teaching series are realized through scientific and humanistic general knowledge, classification culture, interdisciplinary courses, personalized training, expert lectures, and enterprise classes. practical teaching series are mainly manifested through leading project, actual situation case, double tutors' guidance, senior students' guidance, centralized practice and dispersive practice and so on.

Formulate "Theme-project" Practical Teaching Mode and Improve Comprehensive Practice Project System. Based on on-campus training rooms and off-campus practice teaching base, we can cultivate students' innovation ability and practice ability based on the Internet, and change original teaching mode, relying on advantage and resource of enterprises to implement practice teaching mode of subject-project.

Subject Teaching. According to post demand of logistics professional and requirement of talent cultivation, we can sign topic teaching agreement with logistics enterprises, by experienced personnel in logistics industry providing existing logistics problems or what need to be optimized or be resolved. At the same time, professional teachers integrate these problems in accordance with ability requirements of talents training scheme, then classify these problems. Based on existing practice teaching series to conduct theme teaching, enterprise personnel and professional teachers evaluate effect after the students' practical training. Meanwhile, business personnel analyze from perspective of solution projects effectiveness or efficiency and professional teachers analyze from aspects of scheme integrity and systematization.

Teaching of Plan Design and Operation Projects Integrated in Internet Logistics Operation. Relying on existing cooperation enterprise resources, teaching of plan design and operation projects integrated in Internet logistics operation establish a close cooperation relationship with enterprises, which change existing teaching mode and take an introduction the fourth party simulative logistics enterprises invested by cooperation enterprises in accordance with requirements of personnel training. Teachers, abundant practical teaching experience, are responsible for teaching organization arrangement, integrating real cases of enterprises by the way of project management to classify students. Then, students submit project scheme design and operational planning books, which be jointly guided by training teachers and enterprise tutors. Eventually training teachers 
evaluate project effect on campus, at the same time, project schemes are plunged into enterprise actual operation process.

\section{Safeguard measures}

Strengthen Construction of Teaching Staff and Establish High-level Teaching Teams for Double-Professionally-Titled Teachers and Enterprises Mentors. Considering "resource sharing, win-win" as guidance, we can adopt staff with abundant enterprise experience as part-time teachers and university teachers undertake some part-time jobs of enterprises. By means of depth integration of enterprise tutors and teachers, we can build high level teaching teams who understand development present situation of logistics industry and possess solid theoretical foundation and practical ability. At the same time, it encourages higher institutions develop online dominant courses with disciplines advantages, then, establish credit identification management of online courses.

Explore and Establish Credit Management System, Gradually Expand Students' Right to Choose Courses Independently. Guided by credit system, we can implement flexible educational system and independent selection course system, eliminating large amount class and implementing small class teaching. Then, we can establish personal learning account and credit system, setting up various high quality selection courses and allowing students obtain credit through classroom teaching, online learning, self-study, cross major or cross school. Consequently, this mode improve students' independent choice of specialty cognitive ability and understanding ability to promote students' science and humanities general ability.

Build a Flexible and Diversified Teaching Evaluation System Focusing on Feedback. This study is to build flexible and diversified teaching evaluation system, and to provide multiple evaluation function, with the purpose of providing whole process records for learners, including study content, examination and exchange activities, discussion, actual operation, skills training, etc. In the end, it contributes to provide diversified evaluation report for learners. Professional knowledge and professional skill can be subdivided, respectively, taking different evaluation methods. At the same time, it is conducive to attach importance to students' learning process evaluation and increase share of process evaluation, making process evaluation play positive impetus to teaching practice. In general, it is important for improve teaching evaluation feedback, rectify and regulate teaching quality.

\section{Conclusion}

Based on the literature review of existing Internet-based logistics talents in applied colleges and universities, the existing problems of logistics personnel training mode and talents demand analysis of logistics industry development, this paper put forward the core of logistics talents training, which are practical problems solving skills of Internet e-commerce logistics field and practical work abilities of Internet logistics system planning, planning and construction of Internet information systems, Internet e-commerce logistics operations and other. The core of training model is to establish an ecosystem model of logistics talents training "four modernizations" based on Internet era and construct a curriculum structure system based on matrix "platform-module-enterprise curriculum". Finally, this paper assurance training mode implementation by strengthening construction of teaching staff, establishing a credit system of teaching management system and constructing flexible feedback-oriented teaching evaluation system.

For the future work, we will be focusing on implementation of curriculum structure system content. What's more, to ensure smooth implementation of logistics personnel training mode, teaching assurance system should be built from different levels. 


\section{Acknowledgements}

Fund Project: University-level Teaching Reform Project "Innovative Logistics Talent Cultivation Model in Applied Universities Based on Internet Era" (no.:2016Y02), host: Shufan Zhu.

\section{References}

[1] Q. Sheng, Innovation of talent cultivation mode in higher vocational logistics based on Internet of things. China Market, 2015, pp. 16-18.

[2] Q. Xu, Applicability of logistics management personnel training in Internet-education in logistics Internet era. Logistics Engineering and Management, 2015, pp. 143-144.

[3] S.L. Wang, Technical skills demand and constraints analysis of vocational logistics information talents based on internet in higher vocational education. Logistics Technology, 2015, pp. 51-53.

[4] Y. Wang, Undergraduate talents cultivation mode of logistics management in ethnic universities under new situation. Education Teaching BBS, 2015, pp. 145-146.

[5] L. Cai, Cultivation mode of Internet thinking type in higher vocational clothing design. Professional Education BBS, 2015, pp. 56-59.

[6] S. Wu, Problems and strategies for talents mode in advertising design and production professional in the Internet era. Professional Education BBS, 2016, pp. 72-74. 